\title{
Incessant Pleural Drainage - Can It Be a Masquerading Esophageal-Pleural Fistula?
}

\author{
Vijay Kumar Mishra, Rajesh Kumar Singh, Souvik Chaudhuri, Ajay Kumar Singh \\ Department of Critical Care, Bhagwan Mahavir Medica Superspecialty Hospital, Ranchi, Jharkhand, India
}

\section{Abstract}

Spontaneous esophageal-pleural fistula (EPF) is extremely rare. We present a case of a 52-year gentleman who presented with shortness of breath and decreased appetite, whose chest X-ray and ultrasonogram of thorax depicted a pleural effusion like picture. Intercostal drainage tubes were inserted to alleviate his dyspnea. Plain computerized tomography (CT) thorax initially revealed a pleural cyst, which was surgically drained. Subsequent CT thorax with contrast and barium swallow revealed EPF, which was confirmed with endoscopy. Pleural fluid analysis revealed candida as the cause of EPF. Candida as a cause of EPF that too in an nonimmunocompromised patient is very rare. Multidisciplinary approach is required to diagnose and prevent mortality in such cases.

Keywords: Esophageal-pleural fistula, incessant drainage, massive pleural effusion

\section{INTRODUCTION}

Esophageal-pleural fistula (EPF) is rare and a spontaneous one even rarer. ${ }^{[1]}$ Causes of EPF are mostly iatrogenic, such as after esophageal instrumentation and postpneumonectomy, due to esophageal ulcer, corrosive esophagitis, Boerhaave syndrome, or neoplasm. ${ }^{[2-7]}$ The computerized tomography (CT) thorax may give a picture like that of hydropneumothorax, supradiaphragmatic, or infradiaphragmatic abscess. ${ }^{[3]} \mathrm{EPF}$ can cause complications such as mediastinitis, empyema, and aspiration pneumonia and hence should be diagnosed as early as possible. ${ }^{[2]}$

Contrast-enhanced $\mathrm{CT}$ along with orally administered contrast is the imaging of choice. ${ }^{[7]}$ There has been only one EPF case reported in a nonsurgical, nonimmunocompromised patient where candida was the cause. ${ }^{[6]}$

\section{Case Report}

A 52-year-old man was admitted to our hospital with chief complaints of shortness of breath, orthopnea along with decreased appetite and easy fatiguability. He did not have any other comorbidities. There was a history of regular alcohol consumption for the past 15-20 years. On admission in the emergency department, his vitals were heart rate

\begin{tabular}{|l|l|}
\hline \multicolumn{2}{|c|}{ Access this article online } \\
\hline Quick Response Code: & Website: \\
\hline & www.ijrconline.org \\
\cline { 2 - 2 } & \\
\hline
\end{tabular}

$120 / \mathrm{min}$, blood pressure $140 / 100 \mathrm{mmHg}$, and saturation of $90 \%$ on room air. He was tachypneic with respiratory rate of about $35-40 / \mathrm{min}$ and prominence of accessory muscles of respiration. He was put on noninvasive ventilation, with spontaneous timed mode. He was afebrile at the time of admission. On auscultation, air entry on the right side of the thorax was not audible. Ultrasonogram (USG) thorax revealed massive right-sided pleural effusion, which was corroborated with chest X-ray (CXR) [Figure 1].

The patient was immediately shifted to the intensive care unit. Since the patient was dyspneic and CXR revealed right-sided pleural effusion with mediastinal shift, a 32 French intercostal drain (ICD) was inserted in the right fourth intercostal space. There was drainage of purulent, slightly hemorrhagic material from the ICD. The breathlessness of the patient was relieved. However, since there was drainage of more than $1 \mathrm{~L}$ of purulent material through the ICD, the ICD was clamped to prevent reexpansion pulmonary edema.

Address for correspondence: Dr. Souvik Chaudhuri, Bhagwan Mahavir Medica Superspecialty Hospital, Ranchi - 834 009, Jharkhand, India. E-mail: souvikchaudhuri1207@gmail.com

This is an open access journal, and articles are distributed under the terms of the Creative Commons Attribution-NonCommercial-ShareAlike 4.0 License, which allows others to remix, tweak, and build upon the work non-commercially, as long as appropriate credit is given and the new creations are licensed under the identical terms.

For reprints contact: reprints@medknow.com

How to cite this article: Mishra VK, Singh RK, Chaudhuri S, Singh AK. Incessant pleural drainage - Can it be a masquerading esophageal-pleural fistula? Indian J Respir Care 2019;8:60-2. 
Repeat CXR revealed the correct position of the ICD, along with decrease in pleural effusion. However, on unclamping the ICD again, there was incessant flow of purulent material from the ICD. This prompted us to get a CT thorax done, which revealed a saccular structure in the right hemithorax, suggestive of a large pleural cyst [Figure 2].

Surgical consultation was given, and after explaining to the patient and attendants, thoracotomy was done. About $3 \mathrm{~L}$ of pus was drained from the cystic sac, and decortication was done. Another ICD was inserted by the surgeon intraoperatively, and the patient showed signs of improvement postextubation.

Once oral liquid diet was started, his breathlessness again aggravated and the ICD drained material suggestive of the feed. This raised our suspicion of a possible EPF, and contrast CT of thorax with oral contrast as well as a barium swallow confirmed our diagnosis [Figures 3 and 4].

Gastroenterology opinion was taken, and endoscopy revealed a fistula in the lower one-third of the esophagus, with leaking of the barium through the fistula, eventually draining through

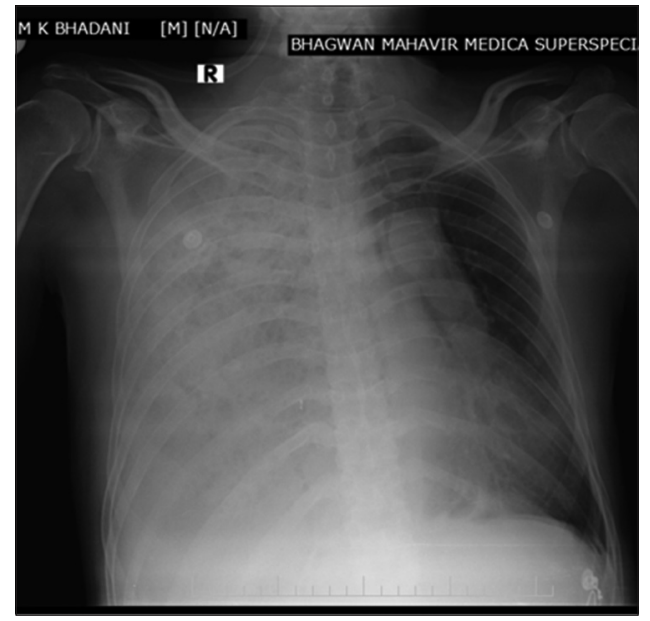

Figure 1: Chest $\mathrm{X}$-ray showing massive pleural effusion on the right side with mediastinal shift

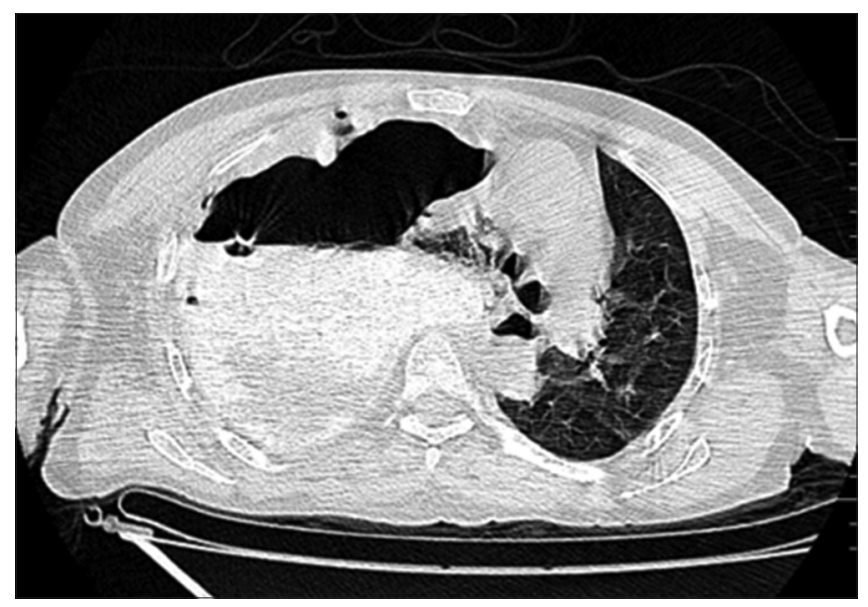

Figure 3: Contrast computerized tomography showing hydropneumothorax on the right side the ICD [Figure 5]. A nasojejunal tube was placed under endoscopic guidance, and he was planned for thoracotomy and closure of fistula.

\section{Discussion}

Our patient presented with dyspnea and orthopnea, and the CXR and USG thorax revealed massive right pleural effusion with mediastinal shift. To relieve his respiratory distress, immediate ICD was done. However, when his ICD was excessive and was draining material similar to the feeds, it raised a suspicion of EPF. This was similar to the case report by Vyas et al.$^{[1]}$ Initial plain CT thorax was misleading, and even after the surgical decortication of the pleural cystic sac, his CXR worsened and feeding liquids were observed in the ICDs. The contrast CT thorax and barium swallow confirmed EPF. Pleural fluid culture grew Candida krusei. He was administered broad-spectrum antibiotics and intravenous fluconazole. Candida as a possible cause of EPF in a nonimmunocompromised individual who has never had a surgery or esophageal instrumentation has been reported only once before, and this makes our case unique. ${ }^{[6]}$

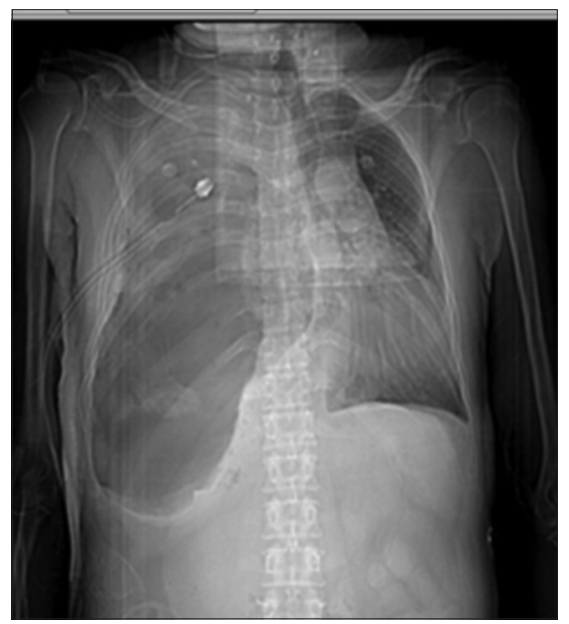

Figure 2: Plain computerized tomography thorax showing saccular structure suggestive of pleural cyst/empyema

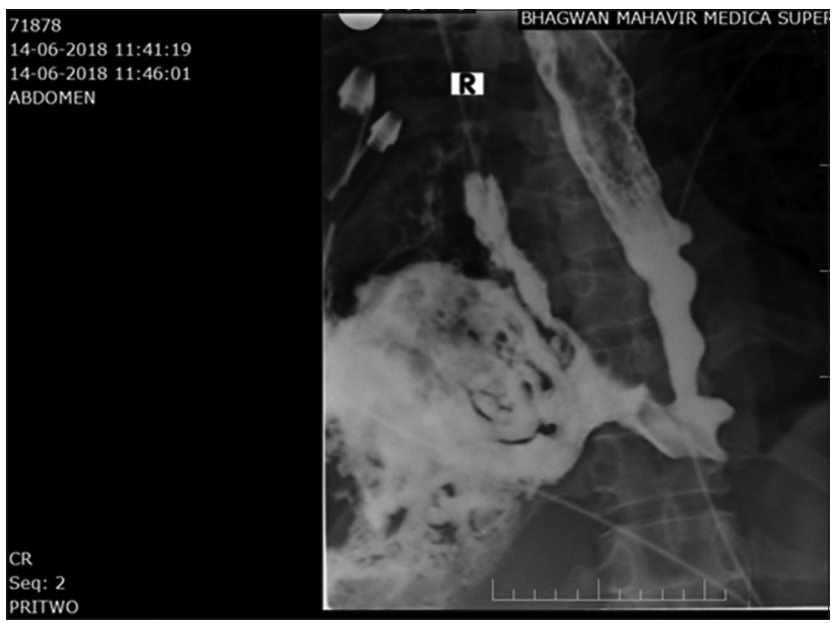

Figure 4: Barium swallow showing the esophageal-pleural fistula 
Mishra, et al.: Case of masquerading esophageal-pleural fistula

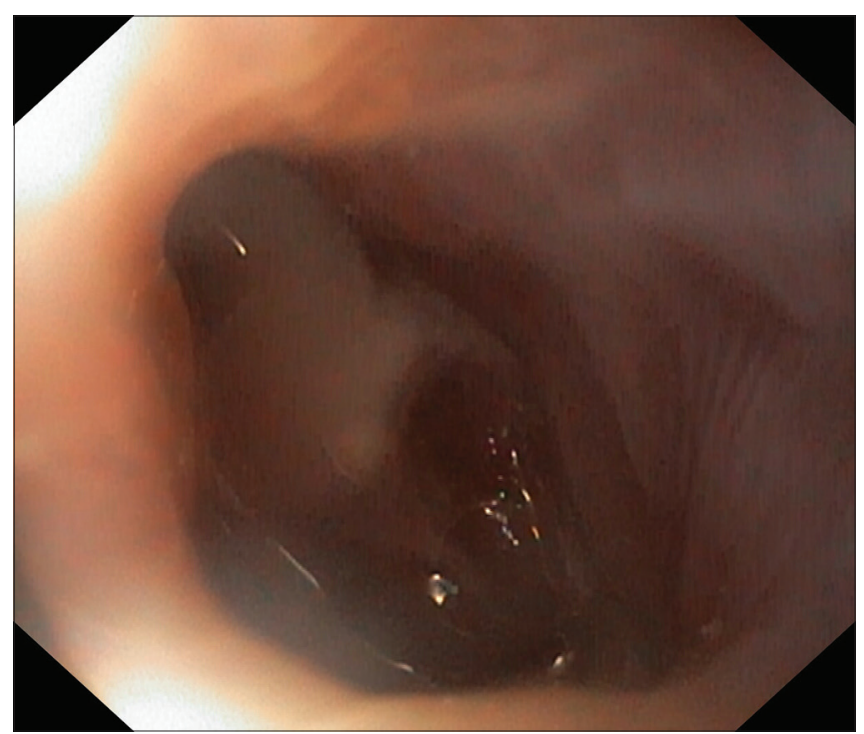

Figure 5: Endoscopy revealing the esophageal-pleural fistula

In our case, forceful vomiting postalcohol consumption along with Candida esophageal infection might be the causes of EPF.

As the patient never underwent any surgery or esophageal instrumentation, EPF was never contemplated initially. Endoscopy revealed the site of EPF as lower one-third of esophagus, and nasojejunal tube was placed in jejunum to bypass the EPF, which enabled us to administer feeds to the patient and reduced the pleural leak significantly. Management of EPF includes complete drainage of empyema and decortications of cavity along with closure of EPF. EPF can be closed with metal stents, by thoracotomy using muscle flap, or even in some cases by fibrin glue. ${ }^{[8,9]}$

\section{Conclusion}

We must consider EPF as a possible cause of nonresolving empyema thoracis with large amount of intercostal drainage, even in a patient who may not have predisposing factors such as previous surgery, esophageal instrumentation, or being immunocompromised. Early suspicion leads to prompt diagnosis and treatment options, which decreases mortality in such rare and serious scenarios.

\section{Declaration of patient consent}

The authors certify that they have obtained all appropriate patient consent forms. In the form the patient(s) has/have given his/her/their consent for his/her/their images and other clinical information to be reported in the journal. The patients understand that their names and initials will not be published and due efforts will be made to conceal their identity, but anonymity cannot be guaranteed.

\section{Financial support and sponsorship}

Nil.

\section{Conflicts of interest}

There are no conflicts of interest.

\section{References}

1. Vyas S, Prakash M, Kaman L, Bhardwaj N, Khandelwal N. Spontaneous esophageal-pleural fistula. Lung India 2011;28:300-2.

2. Wechsler RJ. CT of esophageal-pleural fistulae. AJR Am J Roentgenol 1986;147:907-9.

3. Wechsler RJ, Steiner RM, Goodman LR, Teplick SK, Mapp E, Laufer I, et al. Iatrogenic esophageal-pleural fistula: Subtlety of diagnosis in the absence of mediastinitis. Radiology 1982;144:239-43.

4. Liu PS, Levine MS, Torigian DA. Esophagopleural fistula secondary to esophageal wall ballooning and thinning after pneumonectomy: Findings on chest CT and esophagography. AJR Am J Roentgenol 2006;186:1627-9.

5. Van Den Bosch JM, Swierenga J, Gelissen HJ, Laros CD. Postpneumonectomy oesophagopleural fistula. Thorax 1980;35:865-8.

6. Al-Shawwa B, D'Andrea L, Quintero D. Candida esophageal perforation and esophagopleural fistula: A case report. J Med Case Rep 2008;2:209.

7. Pache G, Thuerl C, Bley T, Kotter E, Ghanem N. Asymptomatic esophago-pleural fistula presenting 35 years after pneumonectomy for tuberculosis. J Thorac Imaging 2005;20:223-5.

8. Deshmukh A, Jadhav S, Kasat S, Deshmukh H, Yadav C, Ramachandran S. Case Report: Spontaneous esophageal pleural fistula. J Pulmon Respir Med 2015;5:259.

9. Khalili A, Steiner R, Fortgang IS. Endoscopic repair of an esophagealpleural fistula with fibrin glue. Gastrointest Endosc 2010;71:AB257-8. 